\title{
Research on innovative design of digital communication of cosmetics advertising
}

\author{
Sun $\mathrm{Lu}^{1}$ \\ ${ }^{1}$ Visual Communication Department Academy of Arts \& Design Tsinghua University Beijing, China
}

\begin{abstract}
The development of digital media has brought substantial changes to the cosmetics advertising communication. In this study, the environment and models of cosmetics advertising communication design in the era of digital media were firstly analyzed in detail, then the problems in the communication design of cosmetics advertising were discussed, and finally innovative strategies for the design of cosmetics advertising communication in the era of new digital media were proposed.
\end{abstract}

\section{Introduction}

The rapid development of the Internet has created a large number of new media, leading to substantial changes in consumers' behavior of media contact and purchase. In the era of independent information dissemination, "decentralization" and the prevailing social media have deprived traditional mass media of communication authority, entitling consumers to interact and share with brands on the top of the communication chain. Consumers and brands play the role of information creators and recipients simultaneously, which realizes the top-level communication between brands and consumers, and between consumers. This paper proposed three innovative design strategies based on the environment and problems of cosmetics advertising communication design in the era of digital media, tried to give an effective guide to designers and cosmetic corporates.

\section{The environment of cosmetics advertising communication in the era of new media}

\subsection{Media environment: advertising communication in the environment of digital media}

During the period of mass communication of information, due to the scarce media resources, communicators have absolute dominance, and brand information is transmitted to consumers in a unidirectional way, with few feedback channels, causing a situation where communicators and receivers are in an unequal position. The "interaction" between brands and consumers also involves the interactive relationship between consumers. With the continuous development of omni-media communication technology, the traditional one-way linear relationship between communicators and information receivers is broken, allowing users to enjoy the initiative to receive, follow, and share information. [1] In the era of digital communication, Internet thinking has become the key to advertising design, which requires brands to put themselves in the position of consumers to understand the real needs of consumers, give play to their creativity and initiative, optimize advertising methods and content, and build the most direct connection with consumers to cultivate consumers' brand loyalty.

\subsection{Audience environment: basic situation of cosmetics advertising audience}

From the perspective of brand preferences of different age groups, Gen $Z$ likes to try different brands, has a strong interest in new brands, and has also begun to purchase high-end cosmetics. With certain accumulated experience, the slightly mature group prefers mainstream brands, and is the main group of cosmetics consumption at the current stage. The mature group has a strong brand stickiness and trusts in the products and brands that they have used for a long time. This group generally has a good economic condition and can afford high-end cosmetics. As shown in the table below, Gen $Z$, as digital natives, has a huge consumption potential in the era of new media. Digital Natives refer to those who were born in a digital network world and are the natives of the digital age. This concept was first proposed by the US educator Marc Prensky [2] to distinguish them from digital immigrants [3], who were born before the digital age and learn new digital technologies and applications through educational learning. (Table I) 
Table1. Cosmetics audience

\begin{tabular}{|c|c|c|c|}
\hline & $\begin{array}{l}\text { Digital natives } \\
\quad(\text { Gen } Z)\end{array}$ & $\begin{array}{c}\text { Digital } \\
\text { immigrants } \\
\text { (Slightly } \\
\text { mature group) }\end{array}$ & $\begin{array}{c}\text { Digital } \\
\text { immigrants } \\
\text { (Mature Group) }\end{array}$ \\
\hline Age & $15-24$ & $25-39$ & $40-54$ \\
\hline $\begin{array}{c}\text { Charac } \\
\text { teristic } \\
\mathrm{s}\end{array}$ & $\begin{array}{l}\text { They have strong } \\
\text { personality and } \\
\text { wear fine } \\
\text { makeup. They } \\
\text { pay attention to } \\
\text { daily cleaning } \\
\text { and favor testers. }\end{array}$ & $\begin{array}{l}\text { They have } \\
\text { fixed and clean } \\
\text { makeup, and } \\
\text { start to buy } \\
\text { products to } \\
\text { prevent early } \\
\text { aging. }\end{array}$ & $\begin{array}{c}\text { They pay } \\
\text { attention to daily } \\
\text { skin care, and } \\
\text { prefer cosmetic } \\
\text { products to wear } \\
\text { an elegant } \\
\text { makeup }\end{array}$ \\
\hline $\begin{array}{c}\text { Brand } \\
\text { prefere } \\
\text { nces }\end{array}$ & $\begin{array}{l}\text { They are willing } \\
\text { to try different } \\
\text { brands, have a } \\
\text { strong interest in } \\
\text { new brands, and } \\
\text { gradually dip into } \\
\text { high-end brands. }\end{array}$ & $\begin{array}{l}\text { They have } \\
\text { certain brand } \\
\text { awareness and } \\
\text { prefer } \\
\text { mainstream } \\
\text { brands. }\end{array}$ & $\begin{array}{c}\text { They have strong } \\
\text { brand stickiness, } \\
\text { well economic } \\
\text { conditions, and } \\
\text { favor high-end } \\
\text { brands }\end{array}$ \\
\hline
\end{tabular}

\section{The model of cosmetics advertising communication in the era of new media}

\subsection{The communication model based on traditional media}

As mentioned above, despite new models of advertising communication and reception brought by the development of digital media to brands and consumers, traditional media are irreplaceable. Television and magazine media, outdoor billboards relying on social public facilities, and physical cosmetics shops are still important advertising media for cosmetics brands.

- Traditional TV media: owing to the extremely high communication efficiency and strong communication ability, traditional TV media has always played an important role. In recent years, with the changes in the lifestyles of young people and the emergence of diverse new media, the communication coverage of traditional TV advertising has been reduced, and consumers are no longer willing to accept straightforward advertising in a cramming way. Therefore, brands started to adopt the advertising method of product placement, which means placing brands or products in various TV variety shows, popular TV series and evening shows with high audience rating of major channels. For example, in the variety shows, "MARUBI" appearing in the show poster as the title sponsor, PECHOIN showing in The Voice of China, and the specially designed advertising of CHCEDO which is eye-catching in Divas Hit The Road all are successful cases of product placement.

- Magazine media: consumers are accustomed to obtaining the latest information and reviews on consumer products such as cosmetics and luxury goods from fashion magazines. Cosmetics brands can be presented on the inside pages of the magazine through direct advertising, or the products can be shown in the content of the magazine through advertorial. Fashion magazines have always exerted a subtle influence on consumers' purchase behavior. The recommendations of senior fashion editors are more trustworthy than various "celebrity" advertisements in new media. Cosmetics brands always compete for the most popular fashion magazine in print advertisements. Nowadays, the rise of new media has gradually weakened the advantage of traditional fashion media, and major magazines have successively launched "online editions" for readers to read at any time.

- Traditional outdoor media: in closed subways, buses and elevators, there is low interference for advertising communication, and compulsive reading and repeated reading of advertisements can be achieved to a certain extent. Meanwhile, various groups of audience can be covered, so that online and offline customer groups can be attracted to brand stores in a more effectively manner.

\subsection{The communication model based on new media}

The development of digital media has greatly enhanced the effectiveness of information transmission. On the one hand, digital media has extremely large information carrying capacity and is free from the limitations of time and space; on the other hand, as strongly interactive media, its communication is more targeted, and the audience preferences can also be accurately captured. The cost of advertising on digital media is also low. Digital media has become the key channel of cosmetics advertising communication, such as Weibo, WeChat, livestreaming platforms, e-commerce platforms, brand official websites and other media.

- Weibo: a platform for information sharing, dissemination and acquisition based on user relationships. Weibo is a representative social media of the first generation of web2.0. The main purposes of users of Weibo are to record daily life, entertain and relax, and find groups with similar interests to discuss topics of common interest. With a huge number of users, Weibo has now become the primary platform for many people to obtain information. In particular, Hot Search, which can quickly and accurately reflect the degree and direction of Weibo users' attention to hot topics, has become the channel with the highest exposure on Weibo. Creating topics on Weibo and increasing brand exposure and visibility are crucial methods of cosmetics advertising communication.

- WeChat: the WeChat platform creates a face-to-face window for brands and consumers, enabling product's description, skin care or makeup guidance to be provided to targeted users, so that user's loyalty can be effectively improved while a clear brand image is established. For example, the official WeChat Subscription of Glamourflage updates brand information in real time, provides skin care tips and multi-functional membership services, and develops mini games based on the promotion theme of the season, which effectively enhanced the reputation of the brand and consumers' stickiness to the brand, thereby achieving brand promotion in a sustained way.

- In E-commerce platforms: E-commerce has gradually become one of the largest channels for cosmetics consumption. Data revealed that the online growth of cosmetics accelerated in 2016. In 2019, the sales of cosmetics e-commerce reached 147.3 billion yuan, 
accounting for about $31.5 \%{ }^{1}$. E-commerce marketing appeals to the consumption concept of cosmetics consumers, who not only focus on brand awareness, but also pay attention to whether the information is transparent, the reviews on the product and whether shopping is convenient when they purchase cosmetics online. After the overall IT application of online market products, users will have an easier access to the information of basic functions, prices, experts' recommendation and users' reviews of the products. In this context, consumers are more flexible in making a personalized product selection.

- Livestreaming platforms: the main feature that distinguishes online media from traditional media is interactivity, and livestreaming is a way to maximize realtime interaction. The effect of using cosmetics can be quickly seen. The livestreaming hosts try colors of cosmetics, wear make-up or remove makeup during livestreaming, which allows consumers to see the effect of cosmetics in real-time and arouses their purchase desire. The livestreaming hosts can also interact with consumers in real time and answer their questions online. Especially when Internet celebrities, stars and e-commerce platforms are involved, the promotion effect is even more prominent. Livestreaming marketing has greatly benefited the development of the cosmetics industry. [4] [5]

- Official website of brand: the official website is the platform for showing the brand image most directly. Consumers can obtain the brand information such as brand name, brand visual identifications (logo, color, auxiliary graphics, etc.), brand story, brand concept, products, and new product push from the official website. The brand's official website determines the level and style of the brand. In addition to displaying the brand image, an excellent official website of cosmetics also provides the functions of interacting with consumers and purchase.

- Digital outdoor media: the combination of new materials, technologies, media, and equipment with the form of traditional outdoor media can significantly improve the form of traditional outdoor media. For example, commercial building videos, traffic videos and cinema videos enable brands to launch all-round and point-to-point video advertising, which is closer to consumers and more adapts to the development of channels, so that the promotion effect can be enhanced.

\subsection{The use of combination of media and the manifestation pattern}

Compared with the traditional media, new media is a fresh form of communication based on digital technology and network technology, with smart terminals as the target of communication [6]. With unique advantages in content resources, audience groups, and communication platforms, new media can store massive information, publish content in the form of omni-media, and has flexible and diverse interactions with users. In the omni-media communication context, advertising communication activities inevitably

Data from "Analysis Report on Market Demand Forecast and Investment Strategic Planning for China's Cosmetics Industry" released by Prospective Industry Research Institute use a combination of media. The diversified and personalized interaction forms create rich brand experience, so that consumers can more directly receive the information delivered by the brand and become a secondary communicator more autonomously, thus building a virtuous circle of joint image communication.

Taking Pien Tze Huang which launched a brandexclusive festival "Goddess's Festival" as an example. In 2019, Pien Tze Huang Cosmetics launched a national challenge hashtagged \#Be a Goddess" on the TikTok platform, which had more than 1 billion views in less than 3 days. Meanwhile, promoted by various media such as Weibo and WeChat Subscriptions, offline activities were held nationwide, and consumers were encouraged to share their brand experience in real time during offline activities Through the combination of online and offline campaigns, Pien Tze Huang achieved retail sales of 453 million yuan, an increase of $53 \%$ year-on-year. ${ }^{2}$ With the help of new marketing form and topic, Pien Tze Huang has successfully expanded the brand's influence, and also created new ways of attracting customers for stores.

\section{Problems in the communication of cosmetics advertising in the era of digital media}

\subsection{Diversified advertising communication increases the difficulty in the control and management of brand communication}

Different from the control of brand advertising content in the past, the era of digital media is filled with various information sources, including both brand-led content sources and abundant information from vertical websites. Although multiple sources of information have enriched the channels for consumers to obtain information, the control of brand content dissemination has been hit, which brings more difficulties to the building of brand image. Multi-source and diverse content of advertising communication affects systematic brand communication and will easily destroy the brand image that has been built.

\subsection{Advertising communication focuses too much on ad views while ignores brand image}

In the era of digital media, the correlation between brand ability and short-term sales has been weakened. New brands can also achieve a large sales volume in a short period of time. These brands often obtain a large number of ad views and fans at low cost through word of mouth and efficient advertising, and then efficiently converts views into sales through e-commerce platforms. Therefore, ad views have become a critical factor in brand communication. However, tempted by the benefits of views, cosmetics brands tend to eagerly pursue ad views while ignore the core value of the brand. For example, in 
recent years, cosmetics brands always invited popular idols to be their spokespersons in order to fully convert idols' influences and fans into product sales. However, in this process, many brands only pay attention to the clout of celebrities but ignoring whether the image of the spokesperson is consistent with the brand image. It's often too late for them to realize that the spokesperson's image is not suitable for the brand, and the impact on the brand image is irreversible.

\subsection{The brand's ability to deal with public relations crisis}

Given a context where digital media is infiltrating people's lives, crisis will be more detrimental to brands, and crisis response has become more complicated. Negative events will reduce consumers' reputation, favorability, and loyalty to the brand. Brands are facing increasingly great challenge, and incident crises have become normalized and frequent events. Sometimes, brands cannot distinguish whether they encounter a crisis or just a small incident until public opinions are quickly accumulating on social media-dominated new media, and the brand realizes that the situation is uncontrollable, but has no idea what to do, causing irreversible damage to the brand. The characteristics of social media such as large content, huge amount of information, and rapid change of public opinions often make it difficult for brands to make an effective response immediately.

\section{Measures for the design of cosmetics advertising communication in the era of new media}

\subsection{Communication target: explore needs}

Much of the time most people do not fully understand what they have actually already known, and what they express is not entirely their true intention, because a lot of thinking and cognition are unconscious. Therefore, designers need to explore these potential unconscious demands of consumers and understand people's expectations. Only by using scientific methods and strategies to thoroughly understand consumers can designers design advertisements that touch audience's feelings. In a new media era where information resources are excessive, the content of advertising needs to win the recognition from target consumers, so that they are willing to actively acquire it. The design of the communication content should be based on consumer's "acceptance" in order to obtain consumers' recognition of the brand value. Many people pursue universal values, such as the pursuit of health, peace, love and happiness, and the differences between groups and cultures will be reflected in the differences in the importance of these universal values. For example, digital natives have significantly different values formed by the world outlook, social outlook and the outlook on life from those of digital immigrants. Digital natives pursue individual independence and achievement, diversity, freedom and equality; what digital immigrants pursue are order and stability, and the harmonious coexistence of people and everything with a compromise attitude. In advertising communication design, it is necessary to understand the values and life attitudes of the target consumers, and guide them to recognize the brand value, so as to win the consumers' heartfelt recognition.

\subsection{Communication media: cross-media combination}

Cross-media combination do not stick to the form of specific media, and uses appropriate combination of media to communicate with consumers based on user's consumption behavior. As mentioned above, a single communication channel has little impact on promoting cosmetics advertising communication, and brands should make the most of cross-media combination for advertising communication. For example, a variety of creative activities can be launched to create topics to attract consumers' attention and facilitate interaction with consumers through social media such as Weibo, WeChat and various social apps. Regarding offline activities, interactions with consumers can be realized through popup stores, theme stores, etc., and consumers can be encouraged to express brand experience and problemsolving suggestions through participation. The combination of online and offline activities takes full advantage of mobile cross-platform communication to enable topic content to be quickly shared, bringing an opportunity for brands to interact with consumers in real time, so that consumers will constantly form a positive brand perception, and the consumers' re-creation ability of interactive participation and experience sharing can be enhanced.

\subsection{Content of communication: touching people's feelings}

In the era of digital media, traditional indoctrination-based communication methods are declining. People no longer like rigid communication methods, but favor diversified, gentle, and friendly communication patterns. Emotionbased advertising can achieve emotional resonance with consumers, trigger consumer's feelings, and bring brands closer to consumers, and can also effectively produce the secondary communication by consumers, so as to achieve the effect of "explosive" communication [7]. Taking an advertising clip made by Olay as an example, Olay focuses on the friendship between girlfriends to arouse emotional resonance among female consumers. Based on the understanding of women's fear of aging, Olay uses 3 stories about age and highlights a special affection among females- "friendship between girlfriends" as the core of the propaganda, encouraging all women to face life more courageously with the companionship of their girlfriends, so as to express the brand appeal of "there is an affection that keeps us from the fear of age". Love, friendship, and family have always been used in the emotional marketing of brands, while the friendship between girlfriends has rarely been paid attention to. Although friendship between girlfriends is a kind of friendship, it can strike a deep chord 
in the hearts of female consumers when it is propagated alone. In addition, most female consumers are more emotional and are more likely to purchase due to emotional identification. Therefore, focusing on emotions, Olay can more easily win the recognition and favor of target users.

\section{Conclusion}

The market scale of China's cosmetics industry currently ranks second in the world. With the continuous urbanization and the increase in per capita disposable income in China, the per capita consumption expenditure on cosmetics will further rise. Particularly, the cosmetics market has a great development potential in lower-tier cities. In this paper, based on the current situation of cosmetics advertising communication in the environment of digital media, corresponding strategies were proposed from three aspects: communication target, communication media and the content of communication. The era of digital media has created plenty of opportunities for the communication of cosmetics advertising, but it has also brought great challenges for cosmetics brands. The communication of cosmetics advertising will have more segmented channels and more precise target market.

\section{References}

1. Liao Bingyi, Zheng Jiahui. "Research on Innovated Brand Emotional Marketing Communication in Social Media Environment: Based on Brand Equity Theory Perspective," Journal of Advertising Study, 2019 (5), pp. 46-55.

2. Marc Prensky. From Digital Natives to Digital Wisdom-Hopeful Essays for 21st Century Learning, California CORWIN, A SAGE COMPANY, 2012.

3. Marc Prensky, Digital Matives, Digital Immigrants, Horizon, Charter 5, 2001, PI A New Way to Look at Our selve and Our Kids.

4. Li Ting. Research on livestreaming marketing of cosmetics based on Internet celebrity economy [J]. Economic Research Guide, 2020(20): 89-90.

5. Zhang Yuting, Qian Dake, Liu Xi, Jiang Chunjie, Lou Yiying. Analysis of consumers behavior of impulsive purchase under the livestreaming of cosmetics [J]. Cooperative Economy\&Science , 2018(01):55-57.

6. Shu Yongping. New Media Advertising. Shanghai Jiao Tong University Press, 2015.

7. Wu Fan. Dancing With Digital Beauties: The Research On Strategic Digital Communication For Cosmetic Brands, Shanghai Jiao Tong University Press, 2017. 